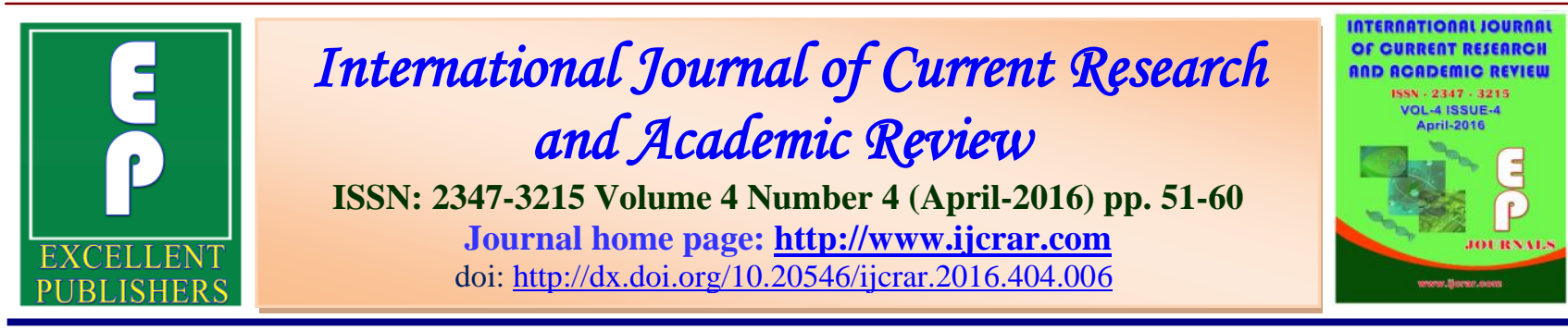

\title{
Dependent Environmental Indicators and Their Effect of Ranking
}

\author{
Ghanima Al-Sharrah, Yusuf I. Ali* and Amir A. Al-Haddad \\ Chemical Engineering Department, Kuwait University, Kuwait \\ *Corresponding author
}

\begin{tabular}{|c|c|}
\hline KEYWORDS & A B S T R A C T \\
\hline $\begin{array}{l}\text { Environmental } \\
\text { Indicators, } \\
\text { world's ecological } \\
\text { system, } \\
\text { harmful } \\
\text { chemicals. }\end{array}$ & $\begin{array}{l}\text { The adverse effect on the environment is mainly due to the release of harmful } \\
\text { chemicals that affects the world's ecological system. The concentrations of } \\
\text { these chemicals are considered as the main indicators for environmental } \\
\text { assessment. In some cases, environmental indicators are highly dependent } \\
\text { and their inclusion will increase the size of experimental data to be collected } \\
\text { and studied. Moreover, it will also increase computational time. This paper } \\
\text { will answer the question if dependent indicators should be included when } \\
\text { environmental decision making is to be made through ranking. It presents a } \\
\text { methodology to implement simple tests on environmental indicators to check } \\
\text { if their inclusion in the decision-making exercise is essential. A case study on } \\
\text { desalination plants in the Arabian Gulf area will be presented. Although } \\
\text { different and advanced desalination methods are being used, their } \\
\text { environmental effects need to be assessed and a reliable methodology needs } \\
\text { to be assessed and a reliable methodology needs to be established to identify } \\
\text { existing harmful plants. The problem of insufficient data for decisions on } \\
\text { desalination plants is resolved by identification of dependent indicators. }\end{array}$ \\
\hline
\end{tabular}

\section{Introduction}

Environmental aspects include potential damage to local and regional environment including humans. Over the last 30 years, there has been a very rapid growth in environment related legislations affecting chemical and power industry. The relation between the industry performance and the environment are complex and not fully understood. The balance recourse used and benefits yield are an individual and social judgment and is clearly difficult to quantify
(Sharrat, 1999). Selecting an appropriate set of indicators to represent multiple and sometimes disparate values is particularly challenging because the interpretation of impacts depends on indicator roles and relationships among indicators (Glenn et al., 2016). However, environmental regulations and indicators are widely used. Using potential ecological indicators is important in assessing ecological risk and/or impact 
evaluations from observations at a molecular level (Jin-Soo, 2015). Regulations now cover products, air and water quality, waste disposal, soil reclamation, noise abatement and related matters. Environmental indicators cover wide range of aspects. However, the most important amongst these is chemical effect and/or concentration. Industrial chemical risk ranking has received the most attention, and several systems have been used, for example, to determine which chemical/location should have more environmental regulations. Davis et al. (1994) gave a good review of 51 chemical ranking and scoring systems. They presented, among others, the system method or algorithm, chemicals and data selection approach together with literature resources for ranking chemicals. Strengths of several certification schemes can be combined with research-based indicators, to increase the reliability of environmental assessments (Markus, 2014).

The problem that is usually associated with the environmental indicators is data availability. Environmental justice efforts suffer from incomplete data (Lobdell et al., 2011) and in some special cases the abundant data will result in developing techniques to reduce the model complexity and selecting a model subset data from experiential data (see for example Pavan et al., 2005). This requires preparing as small as possible data set before doing any environmental decision making. The existence of dependent environmental indicators encourages the reduction of data set and this will be studied in this work.

\section{Dependent Environmental Indicators}

The selection of appropriate measures of environmental performance for a process will depend on the nature of the environmental concerns, type and quantity of information available and degree of accuracy required in the representation. Several environmental analysis indicators or attributes have been developed, some of them are internationally known and proven. Some have been used and developed inside companies. The different environmental indicators are suitable for different stages of process development, design and operation. Some can be applied at a very early stage of planning and require an overall knowledge of the system under consideration, and some must be applied onto existing units with full knowledge of all aspects of the unit. It is clear that irrelevant and redundant indicators should be eliminated from environmental analysis or decision making. However, a question is raised: should dependent indicators be eliminated?

In the science field, dependent variable is the variable expected to change whenever the independent variable is changed and correction can be obtained between them. Methods for correlation between data are generally classified as statistical or conceptual. Statistical methods are oriented towards numerical data and create characterization in terms of correlation, statistical distribution, variance (Imam et al., 1993). Conceptual methods are oriented towards qualitative data and rules. Environmental assessment can benefit from consideration of the correlation structure among indicators (Sutherland et al., 2016) and this will help in reducing data collection for the assessment and can provide information about the underlying system and help in constructing a more appropriate environmental model. Dependency between environmental indicators are studies widely in environmental assessment, for example, between dissolved oxygen and $\mathrm{pH}$ (Makkaveev, 2009), $\mathrm{CO}_{2}$ emission and energy consumption (Omri, 2013) and in watersheds (Sutherland et al., 2016). 
Piegorsch and Bailer (2005) showed that environmental data can be modeled as linear, multiple-linear and simple nonlinear models. Al-Sharrah (2011) indicated that when chemicals are studied and they are ranked according to their hazardous effect, the indicators $\left(Y_{1}, X_{1}, X_{2}\right)$ (e.g. threshold limit value, lethal dose ... etc.) can be correlated using multiple linear correlation with a correlation parameter.

$Y_{1}=\rho X_{1}+\sqrt{\left(1-\rho^{2}\right)} X_{2}$

The $Y_{1}$ indicator will have a correlation of $\rho$ with the $X_{1}$ indicator, i.e., statistically, $Y_{1}$ is more significantly correlated to $X_{1}$ than $X_{2}$. It is worth mentioning that correlation between environmental data can be known from an expert knowledge of the system or by statistical methods (e.g. covariance) applied on the environmental data.

\section{Ranking for Decision Making}

Decision-based ranking and scoring systems can be used to focus attention and resources on the largest potential risk or gain. The decision is usually the final stage of an exercise which started with data collection of some objects and their corresponding indicators. Examples of objects include projects, chemicals, databases etc. and examples of indicators include prices, environmental releases, physical properties etc. The decision on these objects is to determine the most important objects that cause high loss and thereafter needs attention and/or modification.

Decision-based ranking is used extensively in environmental analysis. Studies include ranking projects (Brans et al., 1986), environmental databases (Brüggemann and Voigt, 1995), pesticides (Halfon et al., 1996), sediment sites (Brüggemann et al., 2001). Industrial chemical risk ranking has received the most attention, and several systems have been used, for example, to determine which chemical plant should have more environmental regulations.

In general, ranking method can be classified as relative ranking and categorize methods. Relative ranking means that an overall rank or score is derived for the objects relative to one another and categorize means that groups of objects are assigned high medium or low rank or selected, non-selected objects, using different comparisons between their indicators. Examples of relative ranking are Copeland method (AlSharrah, 2010), Simple Additive Ranking (SAR) and examples of categorize methods are Hasse diagram (Halfon \& Reggiani, 1986). Some of the methods are parametric methods i.e. that a decision maker should provide information or judgment to combine the different indicators in order to obtain the rank. A simple example is when weights assigned to the indicators are to be in a form suitable to be aggregated into a single number from which a rank can be obtained. SAR is simply ranking of objects with respect to each indicator separately, and then subsequent aggregation of the weighted ranks by arithmetic mean. The Hasse diagram and the Copeland method are considered non-parametric method that have been used extensively in decision-based ranking, for example (Brüggemann and Voigt, 1995). A representation of the decision making from SAR with equal weights and Copeland are presented in Figure 1. Both of these methods depend on comparison of indicators however their final results may differ.

Other useful and simple relative or total ranking methods are discussed in (Pavan and Todeschini, 2004). For $R$ indicators and $I$ objects and possible weights $w$ for the 
indicators, the following are two widely used total ranking methods:

\section{Desirability Function}

The approach of the desirability function is to define a desirability function for each indicator in order to transform values $y$ of the indicator to some scale

$d_{r}=f_{r}(y) \quad 0 \leq d_{r} \leq 1 \quad r=1,2, \cdots, R$

The overall desirability is calculated by combining all the desirability through a geometrical mean.

\section{Utility Function}

The approach is very similar to the desirability function; each indicator is independently transformed into a utility function. However, subsequent aggregation of the weighted function is done by an arithmetic mean.

\section{Methodology}

As mentioned earlier, correlations relating environmental data recommended by Piegorsch and Bailer (2005) are linear, multiple-linear and simple nonlinear models. Our specific approach in studying dependent environmental indicators is to know which type from the above correlations affects environmental decision making when it is done by ranking. First, random data were used to provide the above mentioned dependencies and later decision making was generated from the data using different ranking methods; and finally case studies will be presented using real data.

Three types of models between environmental data will be studied, linear:

$Y_{1}=a_{0}+a_{1} X_{1}+\varepsilon_{1}$
Where $Y_{1}, X_{1}$ are environmental indicators, $a_{0}, a_{1}$ are model parameters and $\varepsilon_{1}$ is the additive error term and

\section{Multiple linear}

$Y_{1}=\rho X_{1}+\sqrt{\left(1-\rho^{2}\right)} X_{2}$

Where $\rho$ is the correlation coefficient.

\section{Simple Non-linear}

$Y_{1}=a_{2} X_{1}^{2}+\varepsilon_{1}$

At this stage of analysis, random numbers will be used to test the effect of environmental correlations on decisionsmaking. Steps are as follows:

1. Original Data: Sequences of uncorrelated normal distributed random indicators $X_{l}$, $X_{2}, . . X_{n}$ for hypothetical objects $\mathrm{Obj}_{1}$, $\mathrm{Obj}_{2}, \ldots \mathrm{Obj}_{m}$ are generated using Excel.

2. Extended Data: A correlation model is selected and a dependent indicator $Y_{1}$ is calculated for all objects using that correlation.

3. Decision ranking: Ranking is obtained using the original and extended data. Results of ranking will place the objects (assigned a numerical rank) from top to bottom to represent the most and the lease important object i.e. decision-making.

4. Comparison: Ranks from original and extended data are compared using the Pearson product-moment correlation Coefficient (PPMC).

Random data were generated using Excel with sizes up to 10 objects with 8 indicators. To apply the Copeland ranking method, a program was written in MATLAB (2010); however for other ranking methods, the 
computations were performed using the DART (2010) software. These methods include Desirability, Utility $\bar{\xi}$ and Simple additive ranking.

Results show that ranking results were not highly affected by the addition of a correlated data. The PPMC ranged from 0.9805 to 0.9238 and this means that if correlated environmental data exist in a decision making exercise, their exclusion will not affect the ranking of objects in the exercise. This is very helpful in cases of incomplete data sets and/or for large data sets. The following case study will present this result on real data.

\section{Case Studies}

Desalination plants and their environmental impact into seawater

Desalination was first used by Greek sailors in the 4th century BC to create drinking water by evaporating seawater. Today there are many technologies used for desalination that can process more than 1 million cubic meters per day. The selection of the desalination process is typically based on different operational parameters such as the availability of a raw water or energy source (e.g., seawater vs. brackish water or lowcost heat vs. electricity), the product water demand, intended use and product water quality specifications (industrial vs. municipal use), or the technical know-how, capacity and costs to build, maintain and operate the plant (Tsiourtis, 2001).

The two main desalination technologies are membrane by Reverse Osmosis (RO) and Thermal by Multi Stage Flash (MSF) desalination. Reverse Osmosis (RO) desalination uses the principle of osmosis with hydraulic pressure as a driving force to remove salt and other impurities, by transferring water through a series of semipermeable membranes. Multi Stage Flash (MSF) desalination uses heat to evaporate and condense water to purify it through different stages with different pressures. Other new technologies are emerging now such electrodialysis as (ED) pressureretarded osmosis (PRO). These new technologies need to be evaluated against the existing ones in terms of sustainability, efficiency and reliability.

The increases in desalination plants in many sea regions especially in the Arabian Gulf and the growing number of industrial-sized facilities raises concerns over potential negative impacts of the technology on the environment. The impacts of a seawater desalination plant on the marine habitat depend on the physical and chemical properties of the discharge streams. Therefore, a good knowledge of both the effluent properties and the receiving environments is required in order to evaluate the potential impacts of desalination plants on the marine environment which has a considerable amount of uncertainty.

This work is aimed for environmental assessments and decision making framework for desalination plants using data about the chemical and physical discharges into the sea and their marine ecological effects. The assessment is done using ranking. Special attention is given to the Arabian Gulf where $50 \%$ of worldwide seawater plants operate. Desalination of water is an important method for solving water shortage in Arabian Gulf countries; however, its adverse environmental effects have started appearing in shallow Arabia Gulf.

Several issues must be addressed for any environmental evaluation of desalination. The resulting brine must be disposed off in such a way with minimum impact to the 
environment. All desalination plants use chemicals as part of the pre-treatment process of the feed water, and for posttreatment process of product water. This practice results in discharge of liquid wastes such as disinfectants (Chlorine and biocides), de-fouling and antiscalant agents along with the brine.

Discharged brine contains low concentrations of metal ions resulting from corrosion, namely copper, nickel, chromium and iron. These concentrations are profoundly increased with acid cleaning of the plants.

In desalination studies, the effects on environment are studied to a limited extent. Roberts et al. (2010) noted that a large proportion of the published work is descriptive and provides little quantitative data that can be assessed independently. Most studies study temperature, salinity, chemical disposals and temperature. Water temperature is one of the most important characteristics of sea environment, affecting dissolved oxygen and chemical and biological processes. Dissolved oxygen and temperature are two fundamental measurements of sea productivity and health with clear dependent relation between them. Also, it is shown that the changes of the $\mathrm{pH}$ values are nonlinear relative to the content of oxygen (Makkaveev, 2006).

Bu-Olayan and Bivin (2006) has reported trace metal levels in sea water from five sites of Kuwait Bay where many desalination plants are present.

They reported five metals during harmful algal blooms and non-harmful algal bloom for both seawater and ctenophore? samples in two seasons, summer and winter forming a data matrix with 5 objects (sites) and 40 indicators $(5$ metal concentration in 2 samples in 2 seasons). The metal concentrations are highly linearly correlated and if this data is used for ranking sites, then a reduction can be done using one of the metals only.

This leads a reduced data matrix of 5 objects (sites) with 8 indicators (metal concentration in 2 samples in 2 seasons). Results from both the original and reduced data matrix gave the same decision making; ranking sites from most contaminated to the lowest as: Site-III (Khanma) - Site-IV (Towers) Site-V (Salmiya) - Site-II (Doha) - Site-I (Subiyah).

Another case study is based on the data studied by Modamed et. al, (2005) and shown in Table 1.

The indicators are the rows of Table 1 and the objects to be ranked are the columns and they represent desalination plants in the GCC area. It is clear that some data are missing from Table 1 and if a decision is to be made about which of the above plants are affecting the environment, the problem of missing data should be solved.

Alternatively, a good justification has to be given to exclude the incomplete indicators. It would be possible to exclude incomplete indicators if a relation can be found with other indicators or if they are irrelevant to the environmental objective. Starting with $\mathrm{SiO}_{2}$, this chemical is considered to be safe by the world health organization (WHO) and it's actually a dietary requirement for various organisms; therefore it can be safety excluded from the environmental analysis.

The next is Carbonate $\left(\mathrm{CO}_{3}^{-}\right)$, this ion together with the bicarbonate is highly correlated to the $\mathrm{pH}$ (Holmes-Farley, 2002). Therefore, it can be removed from the data set before ranking the plants. Using all the discussed ranking methods i.e. Copeland, 
Int.J.Curr.Res.Aca.Rev.2016; 4(4): 51-60

SAR, Utility and desirability ranking results indicate that the desalination plants can be ranked from most hazardous to the lowest as: Umm Alquain, Alssadanat, then Hamriyah.

Table.1 Chemical Composition of Reject Brine from Inland Desalination Plants in GCC Countries (Mohamed et al., 2005)

\begin{tabular}{|c|c|c|c|}
\hline Parameter & $\begin{array}{l}\text { Alssadanat, } \\
\text { Oman }\end{array}$ & $\begin{array}{c}\text { Umm } \\
\text { Alquain, } \\
\text { UAE }\end{array}$ & $\begin{array}{l}\text { Hamriyah, } \\
\text { Sharjah, UAE }\end{array}$ \\
\hline $\mathrm{Ca}^{++}, \mathrm{mg} / \mathrm{l}$ & 923 & 202 & 173 \\
\hline $\mathrm{Mg}^{++}, \mathrm{mg} / \mathrm{l}$ & 413 & 510 & 311 \\
\hline $\mathrm{Na}^{++}, \mathrm{mg} / \mathrm{l}$ & 2780 & 3190 & 1930 \\
\hline $\mathrm{K}^{++}, \mathrm{mg} / \mathrm{l}$ & 81.5 & 84.5 & 50.7 \\
\hline $\mathrm{Sr}^{++}, \mathrm{mg} / \mathrm{l}$ & 28.2 & 21.1 & 14.2 \\
\hline Sum cation, meq/l & 203.06 & 192.98 & 119.48 \\
\hline $\mathrm{pH}$ & 7.21 & 7.54 & 7.66 \\
\hline $\begin{array}{l}\text { Electrical conductivity, } \\
\mathrm{mS} / \mathrm{cm}\end{array}$ & 16.8 & 14.96 & 127.41 \\
\hline $\mathrm{TDS}, \mathrm{mg} / \mathrm{l}$ & 10553 & 10923 & 7350 \\
\hline $\mathrm{NO}_{3}, \mathrm{mg} / \mathrm{l}$ & 7.2 & 27.4 & 15.9 \\
\hline $\mathrm{F}^{-}, \mathrm{mg} / \mathrm{l}$ & 0 & 1.6 & 1.3 \\
\hline $\mathrm{Cl}^{-}, \mathrm{mg} / \mathrm{l}$ & 4532 & 4108 & 2933 \\
\hline $\mathrm{SO}_{4}, \mathrm{mg} / \mathrm{l}$ & 1552 & 2444 & 1537 \\
\hline $\mathrm{SiO}_{2}, \mathrm{mg} / \mathrm{l}$ & NA & 164.09 & 133.71 \\
\hline Carbonate $\left(\mathrm{CO}_{3}^{-}\right)$ & NA & NA & NA \\
\hline Bicarbonate $\left(\mathrm{HCO}_{3}^{-}\right)$ & 466 & 656 & 753 \\
\hline $\mathrm{N}^{-}$ & 1.6 & 6.2 & 3.6 \\
\hline Sum anions, meq/1 & 167.88 & 198.05 & 127.41 \\
\hline Ion balance & 9.48 & 4.02 & -3.21 \\
\hline SAR & 19.12 & 27.2 & 20.3 \\
\hline SER & 59.55 & 71.91 & 70.27 \\
\hline L.I & 1.24 & 1.04 & 1.26 \\
\hline R.I & 4.73 & 5.46 & 5.14 \\
\hline Total ion, mg/l & 10781 & 11245 & 7719 \\
\hline Total alkalinity & 380 & 538 & 617 \\
\hline Total hardness & 4041 & 2630 & 1730 \\
\hline $\mathrm{Fe}, \mathrm{meq} / 1$ & 0.06 & 0.08 & 0.05 \\
\hline
\end{tabular}


Figure.1 SAR and Copeland Ranks

(a)

\begin{tabular}{ccc}
\multicolumn{3}{c}{ Indicators } \\
\hline & $\Delta$ & $\mu$ \\
\hline $\mathrm{a}$ & 0.5 & 0.5 \\
$\mathrm{~b}$ & 3 & 5 \\
$\mathrm{c}$ & 4 & 3.5 \\
$\mathrm{~d}$ & 2 & 4 \\
$\mathrm{e}$ & 2.5 & 1 \\
\hline & $\downarrow$
\end{tabular}

(c)

\begin{tabular}{llllll}
\hline a & B & c & D & e & Copeland
\end{tabular}

\begin{tabular}{|c|c|c|c|c|c|c|}
\hline & & & & & & Rank \\
\hline $\bar{A}$ & 0 & -2 & -2 & -2 & -2 & -8 \\
\hline B & +2 & 0 & 0 & +2 & +2 & +6 \\
\hline $\mathrm{C}$ & +2 & 0 & 0 & 0 & +2 & +4 \\
\hline D & +2 & -2 & 0 & 0 & 0 & 0 \\
\hline $\mathrm{E}$ & +2 & -2 & -2 & 0 & 0 & -2 \\
\hline
\end{tabular}

(b)

\begin{tabular}{cccc}
\hline & Rank $\Delta$ & Rank $\mu$ & SAR Rank \\
\hline a & 5 & 5 & 5 \\
b & 2 & 1 & 1.5 \\
c & 1 & 3 & 2 \\
d & 4 & 2 & 3 \\
e & 3 & 4 & 3.5 \\
\hline & & & $\downarrow$
\end{tabular}

(d)

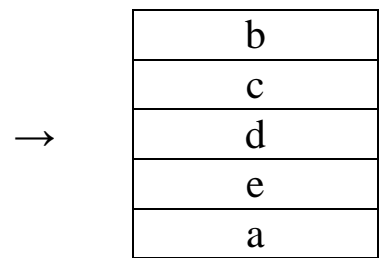

(a) Data matrix. (b) SAR (c) Copeland pair-wise comparison matrix (+1 occurrence of (>), -1 occurrence of $(<), 0$ otherwise). (d) Final relative rank

\section{Conclusion}

One simple method of taking decisions on where to start to minimize the negative impact on the environment is to rank objects (plant, areas, technologies, etc.) according to their released contaminating ability. This work has shown that environmental indicators are correlated and this can be used to understand environmental relation and help in reduction of effort in data collection. The exclusion of correlated environmental indicators will not affect the results of ranking the objects if the ranking was based on comparison indicators, methods such as Copeland, SAR, Utility and desirability. The study applies different ranking methods using some environmental indicators in the GCC area. This work has shown a methodology on how to handle environmental data to reach an environmental decision and how to handle missing data which usually exist in many environmental studies.

\section{References}

Al-Sharrah, K. 2010. Ranking Using the Copeland Score: A Comparison with the Hasse Diagram. J. Chem. Inf. Model., 50: 785-791.

Al-Sharrah, K. 2011. The copeland method as a relative and categorized ranking tool. Statistica \& Applicazioni Special Issue: 81-95.

Brans, J.P., Vincke, Ph., Mareschal, B. 1986. How to select and how to rank projects: the Promethee method. European J. Operational Res., 24: 228-238.

Brüggemann, R., Voigt, K. 1995. An evaluation of online databases by methods of lattice theory. Chemosphere, 31(7): 3585-3594.

Brüggemann, R., Halfton, E., Welzl, G., Voigt, K., Steinberg, C.E.W. 2001. Applying the concept of partially ordered sets on the ranking of nearshore sediments by a battery of tests. 
J. Chem. Information and Computer Sci., 41: 918-925.

Bu-olayan, A., Bivin, V. 2006. Validating Ctenophore Pleurobrachia pileus as an Indicator to Harmful Algal Blooms (HABs) and Trace Metal Pollution in Kuwait Bay.Turkish J. Fisheries and Aquatic Sci., 6: 01-05.

$D A R T$, version 2.05; Institute of Health and Consumer Protection, European Commission Joint Research Centre Web Site. http://ecb.jrc.ec.europa.eu/qsar/qsartools/index.php?c=DART (accessed Feb. 11, 2016)

Davis, G.A., Swanson, M., Jones, S. 1994. Comparative evaluation of chemical ranking and sorting methodologies. University of Tennessee, Center for Clean production and Clean Technologies.

Glenn, D., Sutherlanda, F., Louise Waterhouseb, Jason Smitha, Sari, C., Saundersb, Katherine Paigec, Joshua Maltd. 2016. Developing a systematic simulation-based approach for selecting indicators in strategic cumulative effects assessments with multiple environmental valued components. Ecol. Indicators, 61(Part 2), 512-525.

Halfon, E., Galassi, S., Brüggemann, R., Provini, A. 1996. Selection of priority properties to assess environmental hazard of pesticides. Chemosphere, 33(8): 1543-1562.

Halfton, E., Reggiani, M.G. 1986. On ranking chemicals for environmental hazard. Environ. Sci. Technol., 20: 1173-1179.

Holmes-Farley, R. 2002. Chemistry and the Aquarium: The Relationship between Alkalinity And pH, Volume 1.

http://www.advancedaquarist.com/2002/5/ch emistry
Imam, I.F., Michalski, R.S., Kerschberg, L. 1993. Discovering attributes dependence in databases by integrating symbolic learning and statistical analysis techniques. Proc. Of knowledge Discovery in Database Workshop. AAAI-93 264-275.

Jin-Soo Chang. 2015. Understanding the role of ecological indicator use in assessing the effects of desalination plants. Desalination, 365: 416-433.

Lobdell, D., Jagai, J., Rappazzo, K. 2011. Data Sources for an Environmental Quality Index: Availability, Quality, and Utility Am. J. Public Health, 101(Suppl 1): S277-S285.

Makkaveev, P.N. 2009. The features of the correlation between the $\mathrm{pH}$ values and the dissolved oxygen at the Chistaya Balka test area in the Northern Caspian Sea. Oceanol., 49(4): 466472.

Markus, A., Meyer. 2014. Indicators of bioenergy-related certification schemes - An analysis of the quality and comprehensiveness for assessing local/regional environmental impacts, Biomass and Bioenergy, 65: 151-169.

MATLAB, version 7.1; the MathWorks Inc.: Natick, MA, USA, 2010.

Mohamed, A.M.O., Maraqa, M., Al Handhaly, J. 2005. Impact of land disposal of reject brine from desalination plants on soil and groundwater. Desalination, 182: 411433.

Omri, A. 2013. CO2 emissions, energy consumption and economic growth nexus in MENA countries: Evidence from simultaneous equations models. Energy Economics, (40): 657-664.

Pavan, M., Todeschini, R. 2004. New indices for analyzing partial ranking diagram. Analytica Chimica Acta, 515: $167-181$. 
Pavan, M., Consonni , V., Todeschini, R. 2005. Partial Ranking Models by Genetic Algorithm Variable Subset Selection (GAVSS) Approach for Environmental Priority Settings. MATCH, Commun. Math. Comput. Chem., 54: 583-609.

Piegorsch, W.W., Bailer, A.J. 2005. Analyzing environmental data. Wiley \& Sons.

Roberts, D.A., Johnston, E.L., Knott, N.A. 2010. Impacts of desalination plant discharges on the marine environment: A critical review of published studies. Water Res., 44: 5117-5128.
Sharrat, P. 1999. Environmental Criteria in Design, Computers \& Chem. Engineering, Vol. 23: 1469-1475.

Sutherland, G.D., Waterhouse, F.L., Smith, J., Saunders, S.C., Paige, K., Malt, J. 2016. Developing a systematic simulation-based approach for selecting indicators in strategic cumulative effects assessments with multiple environmental valued components. Ecol. Indicators, 61(Part 2), 512-525.

Tsiourtis, N. 2001. Desalination and the environment. Desalination, 141(3): 223-236.

\section{How to cite this article:}

Ghanima Al-Sharrah, Yusuf I. Ali, Amir A. Al-Haddad. 2016. Dependent Environmental Indicators and Their Effect of Ranking. Int.J.Curr.Res.Aca.Rev.4(4): 51-60. doi: http://dx.doi.org/10.20546/ijcrar.2016.404.006 